ARTICLE

Received 28 Aug 2012 | Accepted 26 Mar 2013 | Published 7 May 2013

DOI: $10.1038 /$ ncomms 2811

OPEN

\title{
A sex-specific transcription factor controls male identity in a simultaneous hermaphrodite
}

Tracy Chong ${ }^{1}$, James J. Collins III', John L. Brubacher ${ }^{2}$, David Zarkower ${ }^{3}$ \& Phillip A. Newmark ${ }^{1,4}$

Evolutionary transitions between hermaphroditic and dioecious reproductive states are found in many groups of animals. To understand such transitions, it is important to characterize diverse modes of sex determination utilized by metazoans. Currently, little is known about how simultaneous hermaphrodites specify and maintain male and female organs in a single individual. Here we show that a sex-specific gene, Smed-dmd-1 encoding a predicted doublesex/male-abnormal-3 (DM) domain transcription factor, is required for specification of male germ cells in a simultaneous hermaphrodite, the planarian Schmidtea mediterranea. dmd-1 has a male-specific role in the maintenance and regeneration of the testes and male accessory reproductive organs. In addition, a homologue of $d m d-1$ exhibits male-specific expression in Schistosoma mansoni, a derived, dioecious flatworm. These results demonstrate conservation of the role of DM domain genes in sexual development in lophotrochozoans and suggest one means by which modulation of sex-specific pathways can drive the transition from hermaphroditism to dioecy.

\footnotetext{
${ }^{1}$ Department of Cell and Developmental Biology, University of Illinois at Urbana-Champaign, 601 South Goodwin Avenue, Urbana, Illinois 61801, USA. 2 Faculty of Humanities and Sciences, Canadian Mennonite University, 500 Shaftesbury Boulevard, Winnipeg, Manitoba, Canada R3P 2N2. ${ }^{3}$ Department of Genetics, Cell Biology and Development, University of Minnesota Medical School, 6-160 Jackson Hall, 321 Church Street SE, Minneapolis, Minnesota 55455, USA. ${ }^{4}$ Howard Hughes Medical Institute, University of Illinois at Urbana-Champaign, 601 South Goodwin Avenue, Urbana, Illinois 61801, USA.

Correspondence and requests for materials should be addressed to P.A.N. (email: pnewmark@life.illinois.edu).
} 
E. volutionary transitions between hermaphroditic and dioecious reproductive states are found in many different groups of animals ${ }^{1-3}$. To understand such transitions, it is important to characterize diverse modes of sex determination and differentiation utilized by sexually reproducing metazoans. Previous studies have described the genetic and/or environmental factors that determine male or female identity in developing embryos of dioecious organisms ${ }^{4-6}$. Following sex determination, a cascade of mechanisms promotes the differentiation of sexual organs and enables germ cells to adopt their sexual identity ${ }^{7,8}$. The sexual fate of germ cells in dioecious organisms may be influenced solely by the sex of the somatic environment ${ }^{9,10}$, or by a combination of cues from both the soma and germ cells ${ }^{11-13}$. In contrast to dioecious organisms, simultaneous hermaphrodites produce gametes and accessory reproductive organs of both sexes.

In spite of all that has been learned about sex determination mechanisms in dioecious animals, little is known about how simultaneous hermaphrodites with no sex chromosomes specify and maintain the fates of male and female germ cells as well as sexually dimorphic somatic structures in the same body. In many dioecious species, doublesex/male-abnormal-3 (DM) domain genes have critical roles in sex-specific development and function ${ }^{14-21}$. To examine whether such sex-specific functions may also function in simultaneous hermaphrodites, we investigated the role of DM domain genes in the planarian, Schmidtea mediterranea.

Here, we show that proper development of the hermaphroditic reproductive system in the planarian $S$. mediterranea is regulated by a gene encoding a DM domain transcription factor, Smed-dmd-1. dmd-1 messenger RNA (mRNA) is expressed in somatic cells associated with the testes and in male, but not female, accessory reproductive organs. Abrogation of $d m d-1$ function results in defects in germline specification and the initial differentiation of the reproductive system. In addition, $d m d-1$ has a male-specific role in the maintenance and regeneration of the testes and male accessory reproductive organs. These results demonstrate that $d m d-1$ is an essential component of pathways responsible for inductive specification of the germline and development of a sex-specific somatic gonadal niche in a simultaneous hermaphrodite. We also show that a homologue of $d m d-1$ exhibits sex-specific expression in S. mansoni, a derived, dioecious flatworm, suggesting a means by which modulation of sex-specific pathways may drive the transition from hermaphroditism to dioecy. Furthermore, our study of $d m d-1$ in two flatworm species provides evidence for the conservation of sex regulatory function between lophotrochozoans and other metazoans.

\section{Results}

Identification of Smed-dmd-1. We identified four genes containing conserved DM domains in the genome of $S$. mediterranea (Supplementary Table S1). Sequence comparisons using BLAST (ref. 22) of the predicted DM domain protein sequences did not detect significant sequence similarities to other DM domain proteins outside the DM domain, consistent with previous phylogenetic analysis of DM domain genes ${ }^{23}$. A maximum likelihood analysis using only the DM domains from each gene was used to generate a phylogenetic tree. Although the tree had poor resolution, and low bootstrap support across most of the topology, it provided evidence of moderate-to-strong relationships between Smed-dmd-1 and homologues in $S$. mansoni (Sm_dmd-1 and Sm_dmd-2, GenBank/EMBL/DDBJ accession numbers XM002575184.1 and XM002574366.1) and the liver fluke, Clonorchis sinensis (dmrt-1a and dmrt-1b, GenBank/EMBL/DDBJ accession numbers GAA52246.1 and
GAA34150.2) (Supplementary Fig. S1). By contrast, dmd-2, -3 and -4 of $S$. mediterranea do not have obvious close homologues in other species based on phylogenetic reconstructions using DM domain or BLAST comparisons using the full protein sequence.

Expression of $\boldsymbol{d} \boldsymbol{m} \boldsymbol{d}-\mathbf{1}$ in sexual and asexual planarians. We used whole-mount in situ hybridization (WISH) to investigate the expression of the four DM domain genes in the planarian, S. mediterranea. Of the four genes, only Smed-dmd-1 mRNA transcripts were detected in the reproductive system. We cloned four splice variants of $d m d-1$, with the longest open reading frame encoding a predicted protein of 341 aa (Supplementary Table S1, Supplementary Fig. S2). An individual planarian's reproductive system consists of both male and female gonads, as well as accessory reproductive organs (for example, oviducts, sperm ducts and seminal vesicles) ${ }^{24}$. In these hermaphrodites, the male gonads are located dorsolaterally and the female gonads are located ventrally at the base of the brain. Germline stem cells associated with the testes and ovaries can be identified by expression of the germline-specific marker, nanos ${ }^{24-27}$ (GenBank/EMBL/DDBJ accession number EF035555.1, Fig. 1a). Notably, asexual strains of planarians that reproduce strictly by transverse fission also contain nanos-positive germ cells, but these cells fail to differentiate ${ }^{24-27}$. In mature sexual animals, $d m d-1$ transcripts were detected by WISH in a subset of cells within and in close proximity to the testes (Fig. 1b), in the brain (br, Fig. 1c), and in male accessory reproductive organs (seminal vesicles, sv; sperm ducts, sd; and penis papilla, pp; Fig. 1c). Using two-colour fluorescent in situ hybridization (FISH), we found that the dorsolateral $d m d$-1-expressing cells reside in close proximity to the testes primordia in recently hatched animals (Fig. 1d), and are found in the developing testes in sexually immature planarians (Fig. 1e). Similarly, in the asexual strain, we detected $d m d-1$ expressing cells in the germ cell clusters along the dorsolateral region of the animal (Fig. 1f), the location of the presumptive testes. We also used transmission electron microscopy (TEM) to visualize the dorsolateral germ cell clusters in asexual planarians. Within these germ cell clusters, we found somatic cells with processes surrounding the germ cells. Somatic and germ cells were distinguishable owing to marked differences in the electron density of their cytoplasm and peripheral condensations of heterochromatin in the somatic cells (Fig. 1g). The somatic cells seen by TEM likely correspond to $d m d$-1-expressing cells. Consistent with this idea, the $d m d$-1-positive cells in the testes of mature sexual planarians did not express germ cell markers, including nanos ${ }^{25-27}$, germinal histone H4 (ref. 27) (GenBank/ EMBL/DDBJ accession number DN306099) and msy4 (refs 28,29) (GenBank/EMBL/DDBJ accession number BK007100.1) (Fig. $1 \mathrm{~h}-\mathrm{j}$ ), suggesting that these are somatic cells of the testes.

To characterize the expression of $d m d-1$ in the brain, we performed two-colour FISH to visualize the neurons and $d m d-1$ positive cells. A subset of $d m d$-1-positive cells in the brain coexpresses chat transcripts, a marker of cholinergic neurons ${ }^{30,31}$, suggesting that the $d m d$-1-expressing cells in the brain are neurons (Fig. 2a). These $d m d$-1-positive neurons are detectable in animals $<24 \mathrm{~h}$ after hatching (Fig. 2b), in asexual animals (Fig. 2c) and also in planarians regenerating new brains (Fig. 2d, Supplementary Fig. S3 for scheme).

Expression of $\boldsymbol{d} \boldsymbol{m} \boldsymbol{d}-\mathbf{1}$ in regenerating planarians. To examine the expression pattern of $d m d-1$ during the regeneration process, sexual planarians were amputated in the region between the ovaries and pharynx (Supplementary Fig. S4a). We performed two-colour FISH at several time points to detect $d m d-1$ and $g H 4$ (to aid in visualization of neoblasts and germ cells) transcripts. At 

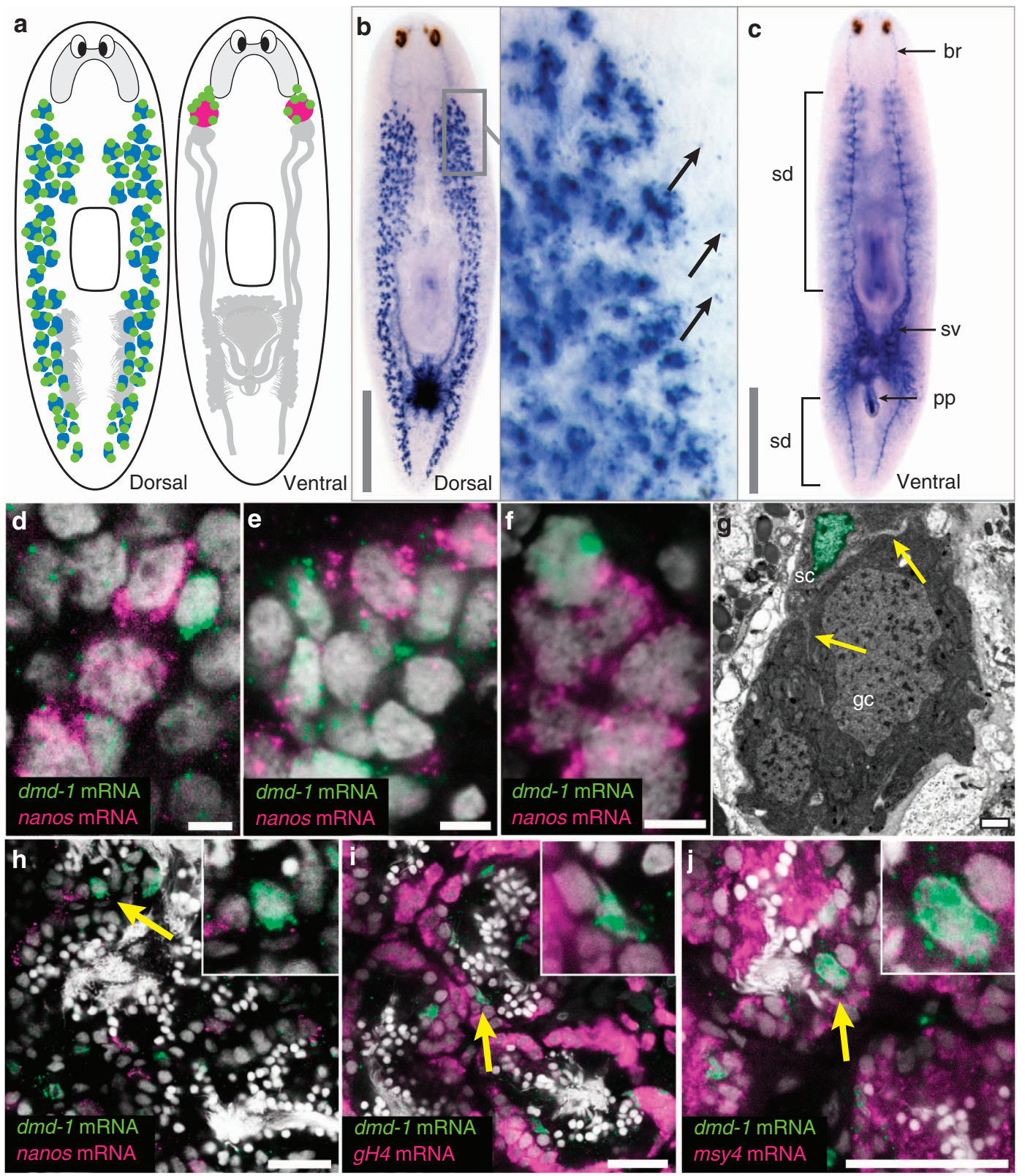

Figure $1 \mid \boldsymbol{d m d}-1$ is expressed in the somatic cells of the male reproductive system. (a) Generalized reproductive system in the sexual planarian. Left, testes (blue) are located dorsolaterally. Right, ovaries (pink) are located more ventrally at base of the brain. nanos-positive germline stem cells of the testes and ovaries (green). Accessory reproductive structures (grey). (b) WISH showing dmd-1 transcripts in and around (arrows) the testes in a sexually mature planarian. (c) Ventral view of the animal showing dmd-1 transcripts in the brain (br), sperm ducts (sd), seminal vesicles (sv) and penis papilla (pp) of a sexually mature planarian. (d-f) Single confocal sections showing two-colour FISH for dmd-1 (green) and nanos (magenta) mRNAs in the testes primordia of animals $<24 \mathrm{~h}$ after hatching (d), developing testes of sexually immature planarians (e) and germ cell clusters in asexuals (f). (g) TEM showing germ (gc) and somatic cells (sc, nucleus pseudo-coloured green, arrows indicate processes) in an asexual planarian. (h-j) Single confocal sections showing twocolour FISH for dmd-1 (green) and germ cell markers (magenta). Somatic cells expressing dmd-1 in the testes do not express germ cell markers nanos (h, 124/125 cells are $d m d-1+/$ nanos - ), gH4 (i, $136 / 136$ cells are $d m d-1+/ g H 4-$ ) and msy4 $(\mathbf{j}, 129 / 129$ cells are dmd- $1+/ m s y 4+$ ). Cell counts were performed from 25-38 testes lobes in at least two animals. Insets, magnified views show cells expressing dmd-1 transcripts (yellow arrows). Scale bars: b,c, $1,000 \mu \mathrm{m} ; \mathbf{d}-\mathbf{f}, 5 \mu \mathrm{m} ; \mathbf{g}, 1 \mu \mathrm{m} ; \mathbf{h}-\mathbf{j}, 25 \mu \mathrm{m}$.

3 days post amputation, we detected $d m d$-1-positive cells in and around the testes lobes in the old tissue, and in the early blastema of the regenerating anterior fragment (Supplementary Fig. S4b). Between 7 and 10 days post amputation, dmd-1-positive cells were present in the blastema, as well as in and around the regressed testes lobes in the old tissue (Supplementary Fig. S4c). At 15 days post amputation, $d m d$-1-positive cells were detected within the new testes lobes that formed in the newly regenerated posterior end of the animal (Supplementary Fig. S4d, right panel, top). We also observed a cluster of $d m d$-1-expressing cells just posterior to the pharynx where the copulatory apparatus is located in sexually mature animals, suggesting that such cells may develop into the male accessory reproductive organs (Supplementary Fig. S4d, left and right panels, yellow box).

$d m d-1$ is expressed in differentiating neoblast progeny. In addition to the $d m d$-1-positive somatic cells in the testes, 

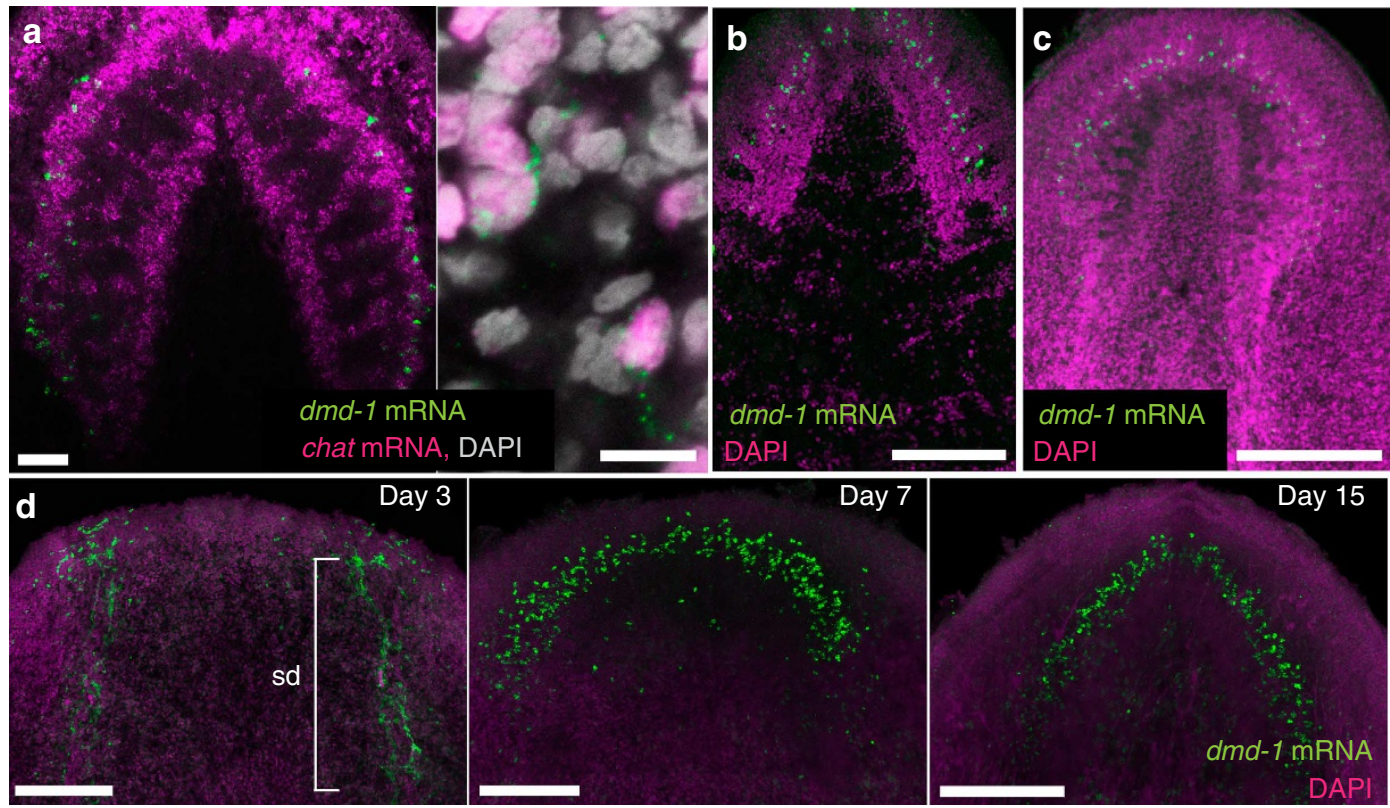

Figure 2 | dmd-1 is expressed in some neurons in the planarian brain. (a) Left, two-colour FISH of $d m d-1$ and chat transcripts in the brain of a sexual planarian. Right, single confocal section showing cells co-expressing dmd-1 mRNA (green) and chat transcripts (magenta), a marker of cholinergic neurons. (b) dmd-1 transcripts, detected by FISH, in the brain of animals $<24 \mathrm{~h}$ after hatching. (c) dmd-1 transcripts, detected by FISH, in the brain of an asexual planarian. (d) FISH to detect dmd-1 transcripts in animals during brain regeneration. The sperm ducts (sd) in the old tissue are still present in day 3 regenerates, but are barely visible owing to regression in day 7 and day 15 regenerates. (a-d) Images shown are confocal projections. Scale bars: a, $50 \mu$ m; b-d, $200 \mu \mathrm{m}$.

dmd-1-positive cells are found in close proximity to the testes lobes in the dorsolateral region. In planarians, pluripotent stem cells (cNeoblasts) provide new cells for regeneration and physiological cell turnover in the animal ${ }^{32}$. Neoblasts are irradiationsensitive and are depleted within $24 \mathrm{~h}$ following irradiation, while their differentiating progeny are lost with different kinetics, becoming depleted several days after irradiation ${ }^{33}$. Neoblasts express abundant smedwi-1 mRNA (GenBank/EMBL/DDBJ accession number DQ186985.1), whereas SMEDWI-1 protein is detected in neoblasts and their differentiating progeny ${ }^{34,35}$. By combined FISH and immunostaining, we detected smedwi-1 mRNA and SMEDWI-1 protein in the dmd-1-positive cells in close proximity to the testes, suggesting that they could be differentiating neoblast progeny (Fig. 3a). To test this idea, we irradiated asexual planarians at $100 \mathrm{~Gy}$ and performed quantitative real-time PCR (qPCR) to assay for $d m d-1$ transcripts. By $48 \mathrm{~h}$ post irradiation, the radiation-sensitive neoblasts and germ cells were depleted, as indicated by a dramatic decrease in smedwi-1 and nanos transcript levels compared with unirradiated controls (Fig. 3b). By contrast, $d m d-1$ transcript levels in irradiated animals decreased by $\sim 50 \%$ relative to unirradiated controls. By day 7 post irradiation, we observed a further decrease of $d m d-1$ transcript levels (Fig. 3b). These results were confirmed by FISH: we observed a reduction of $d m d$-1-positive cells at $48 \mathrm{~h}$ (Fig. 3c) and by day 7 these cells were quite rare (Fig. $3 \mathrm{~d}$ ). In contrast to dorsolateral $d m d-1$ labelling, we found no dramatic differences in the brain of irradiated versus control animals (Fig. 3e). Together, these data suggest that $d m d$-1-positive somatic cells associated with the testes turn over within 7 days and after irradiation these somatic cells are unable to be renewed by neoblasts.

$d m d-1$ is required for male germ cell maintenance in asexuals. To test for a functional relationship between $d m d$-1-expressing somatic cells and nanos-positive early germ cells, we first knocked down $d m d-1$ in asexual planarians, because they lack differentiated germ cells and accessory reproductive organs. qPCR revealed a dramatic decrease in nanos expression in asexual dmd-1-knockdown animals, relative to controls (Fig. 4a). We confirmed this result by FISH to detect the clusters of germ cells co-expressing gH4 and nanos. After dmd-1 RNA interference (RNAi), no gH4/nanos co-expressing germ cells were detectable in the $d m d-1$-knockdown animals (Fig. $4 \mathrm{~b}$ ). These data indicate that $d m d-1$ is required for the maintenance of the dorsolateral presumptive male germ cells in asexual planarians. We have been unable to assay the effect of $d m d-1$ knockdown on female germ cells, as under our experimental conditions we do not detect $\mathrm{gH} 4 /$ nanos co-expressing germ cells in the ovarian region of either the control or RNAi animals. Interestingly, when nanos was knocked down in asexual planarians, the abundance of $d m d-1$ transcripts, as measured by qPCR, was unaffected (Fig. 4c). This result suggests that $d m d$-1-positive somatic cells are not dependent on the presence of germ cells.

dmd-1 is required to regenerate male germ cells de novo. The germline of $S$. mediterranea can be regenerated de novo from somatic tissue ${ }^{27}$, implying that the planarian germline is specified inductivel ${ }^{24}$. Both nanos and $d m d-1$ mRNAs are detectable in sexual animals $<24 \mathrm{~h}$ post hatching (Fig. 1d), suggesting that dmd-1 may be involved in the inductive specification of the germline. To examine this possibility, we knocked down $d m d-1$ in sexual worms, and amputated their heads anterior to the ovaries, generating fragments devoid of reproductive tissue (Fig. 5a). Previous work has shown that de novo specification of the planarian germline occurs between 7-14 days post amputation ${ }^{27}$. Consistent with $d m d-1$ being required for germ cell specification, we find that a majority of $d m d-1$ (RNAi) animals fail to regenerate the dorsolateral clusters of nanos-positive male germ cells (Fig. 5b). 

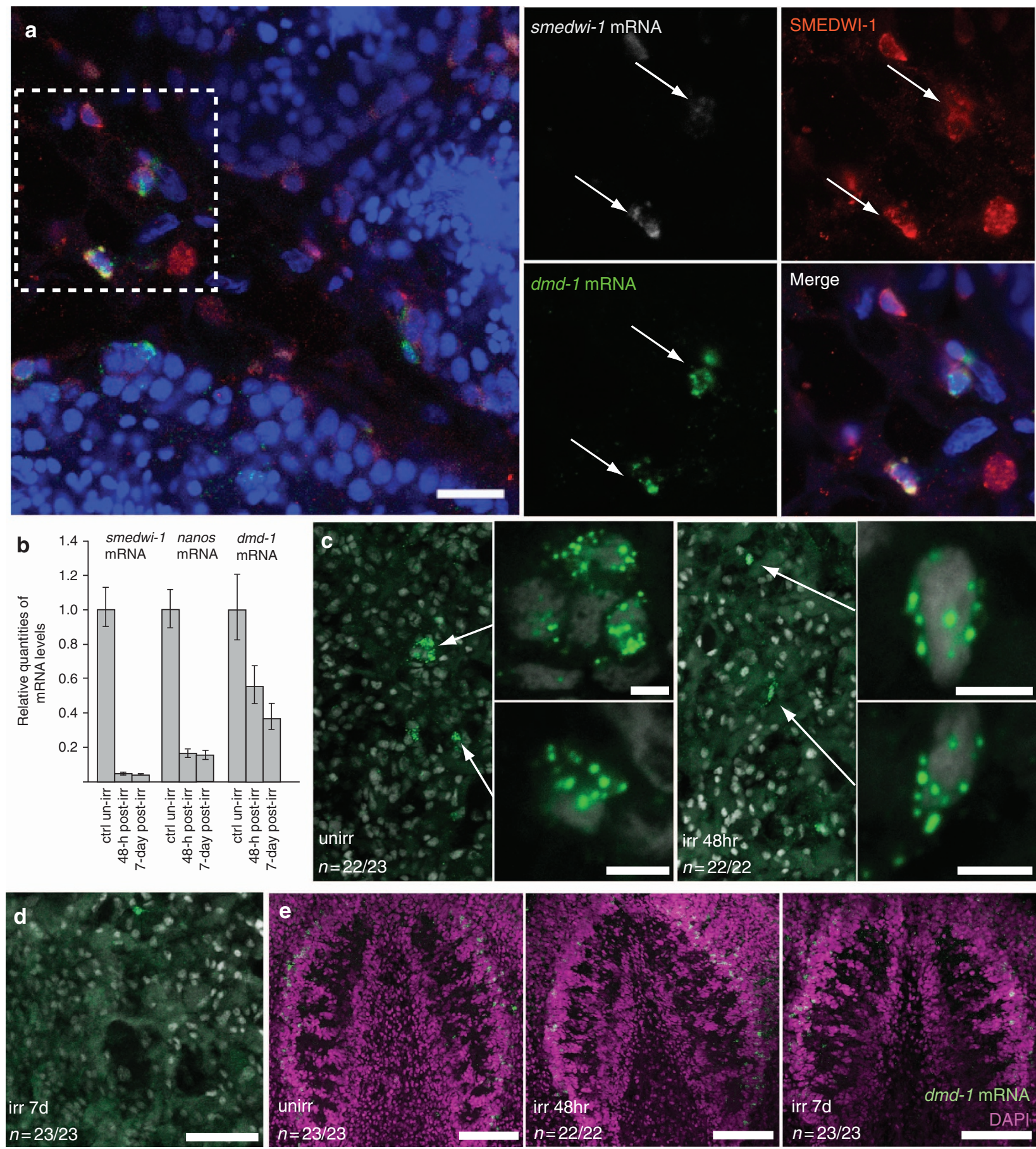

Figure 3 | dmd-1-positive cells in proximity to the testes are differentiating neoblast progeny. (a) Single confocal section showing two-colour

FISH combined with immunostaining in mature sexual animals. $d m d-1$ cells (green) in close proximity to the testes express smedwi-1 transcripts (grey), a marker of neoblasts. SMEDWI-1 protein (red), a marker of neoblasts and differentiating neoblasts is also detected in these dmd-1-positive cells. Arrows indicate $d m d$-1-positive cells within the dashed box. (b) qPCR showing relative levels of smedwi-1, nanos and dmd-1 mRNAs in irradiated (100 Gy) versus unirradiated asexual planarians $48 \mathrm{~h}$ and 7 days post irradiation. Error bars indicate $95 \%$ confidence intervals calculated based on s.e.m., results are the mean from three independent experiments using pools of eight planarians. (c) At $48 \mathrm{~h}$ after irradiation, dmd-7-positive cells (arrows) are present in the dorsolateral region of the animal, albeit in fewer numbers, compared with control animals. Magnified views of cells expressing dmd-1 transcripts (insets). dmd-1 transcripts were detected by FISH. Images shown are single confocal sections. (d) At 7 days after irradiation, dmd-1-positive cells are rarely detectable in the dorsolateral region of the animal. dmd-1 transcripts were detected by FISH. Images shown are single confocal sections. (e) Confocal projection showing that $d m d-1$-positive cells (detected by FISH) are still present in the brain at $48 \mathrm{~h}$ and 7 days after irradiation. Scale bars: $\mathbf{a}, 20 \mu \mathrm{m} ;$ c, $5 \mu \mathrm{m} ; \mathbf{d}, 50 \mu \mathrm{m} ; \mathbf{e}, 100 \mu \mathrm{m}$.

$d m d-1$ is required for the initial development of germ cells. To investigate the role of $d m d-1$ in post-embryonic development of the germline, we initiated $d m d-1$ RNAi in recently hatched planarians ( $<2$ weeks old). At this early stage, nanos-positive germline stem cells are present in the gonadal primordia but the accessory reproductive organs have not yet developed. 
a
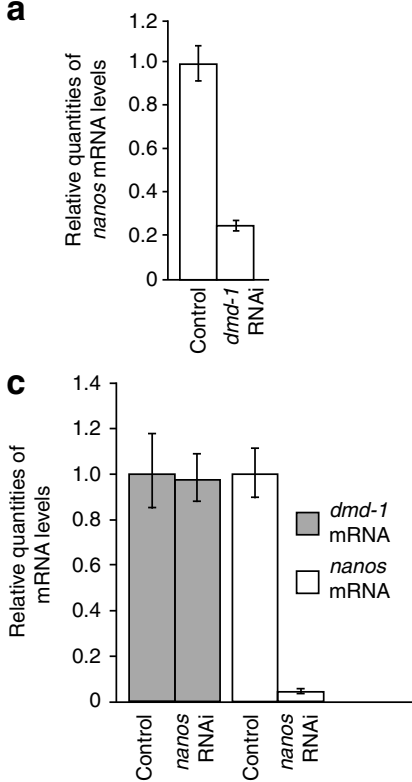
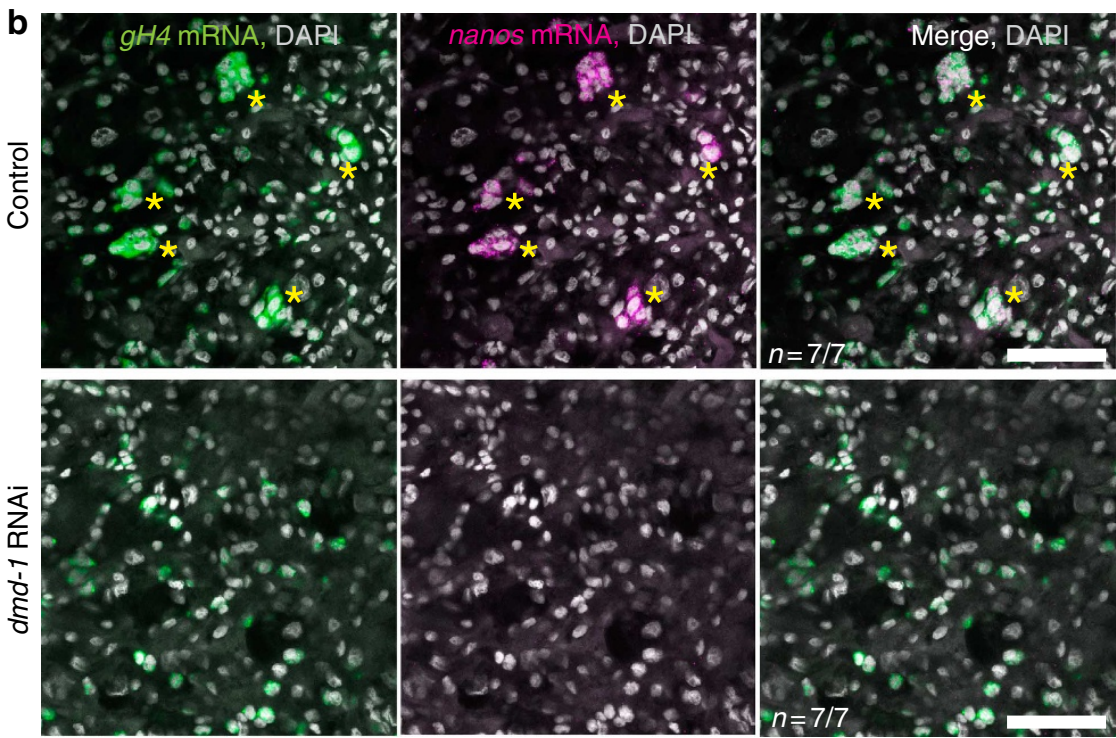

Figure 4 | dmd-1 is required for maintenance of presumptive male germ cells in asexuals. (a) qPCR showing decreased nanos transcript levels in $d m d-1$ (RNAi) versus control asexuals. Error bars indicate $95 \%$ confidence intervals calculated based on s.e.m., $n=8$ individual animals. (b) Loss of $g H 4+/$ nanos + germ cell clusters (asterisks) in dmd-1(RNAi) asexuals. gH4 +/nanos - cells in dmd-1(RNAi) animals are somatic neoblasts. Images shown are single confocal optical sections; $g \mathrm{H} 4$ and nanos mRNAs are detected by two-colour FISH. (c) qPCR showing that dmd-1 transcript levels in nanos(RNAi) versus control asexuals remain unchanged. Error bars indicate $95 \%$ confidence intervals calculated based on s.e.m., results are the mean from three independent experiments using pools of nine planarians. Scale bars: b, $50 \mu \mathrm{m}$.

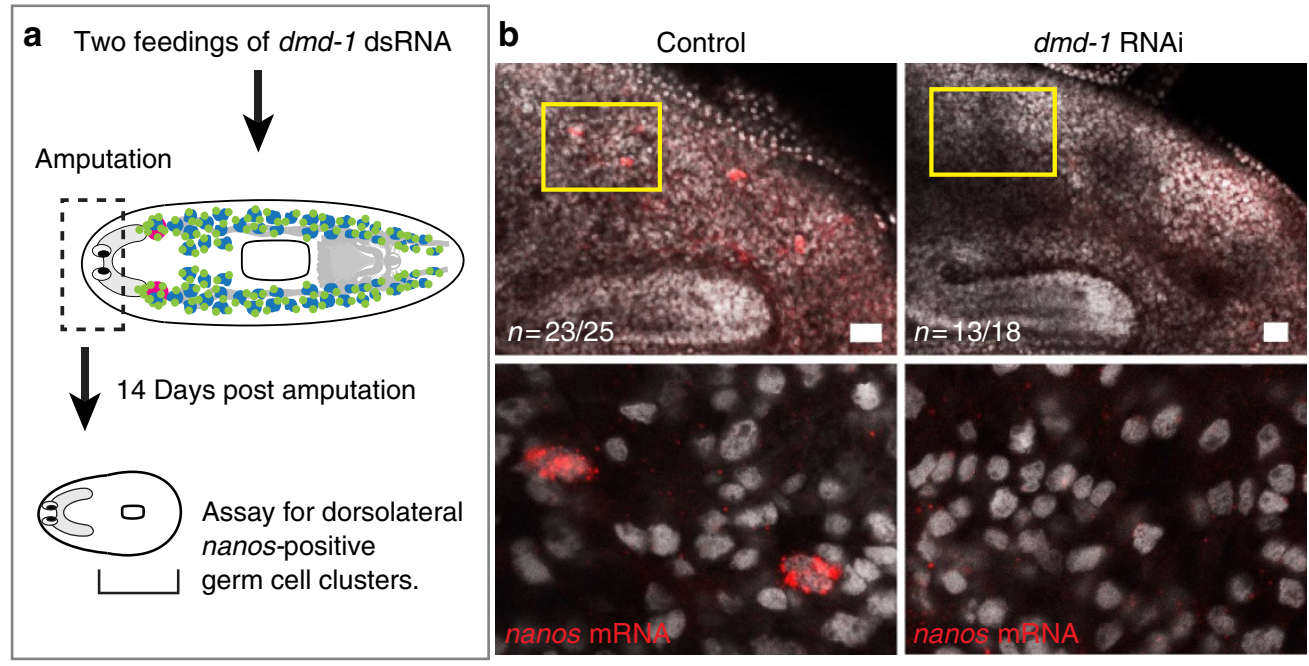

Figure $\mathbf{5}$ | $\mathbf{d} \boldsymbol{m} \boldsymbol{d}-\mathbf{1}$ is required for male germ cell specification. (a) Experimental scheme for generating animals devoid of germ cells and reproductive structures. Only animals that had successfully regenerated (indicated by presence of pharynx) were scored. (b) By 14 days post amputation, planarians devoid of germ cells regenerate dorsolateral nanos-positive cells; $d m d-7(R N A i)$ animals fail to regenerate dorsolateral nanos-positive cells. Images shown are single confocal sections; nanos transcripts are detected by FISH. Scale bars: b, $50 \mu \mathrm{m}$.

When the animals reached maturity, we found that the testes (Fig. 6a,b) and ovaries (Fig. 6c) were absent in $d m d-1$ (RNAi) animals. These results suggest that $d m d-1$ is required for the initial development of both male and female reproductive systems.

dmd-1 is required to maintain male germ cells in sexuals. Next, we examined the role of $d m d-1$ in germ cell maintenance by knocking down $d m d-1$ in sexually mature planarians with fully developed gonads and accessory reproductive organs. In contrast to the previous experiments on hatchlings, only the male reproductive system was affected. The $d m d-1$ (RNAi) animals lost their testes but showed no observable defects in the ovaries (Fig. 7a). These observations indicate that $d m d-1$ is required for the maintenance of the male, but not the female, gonads in S. mediterranea.

$d m d-1$ is required to regenerate male reproductive organs. Seeing the difference in phenotype between $d m d-1$ knockdown in hatchlings versus sexually mature planarians, we also examined 

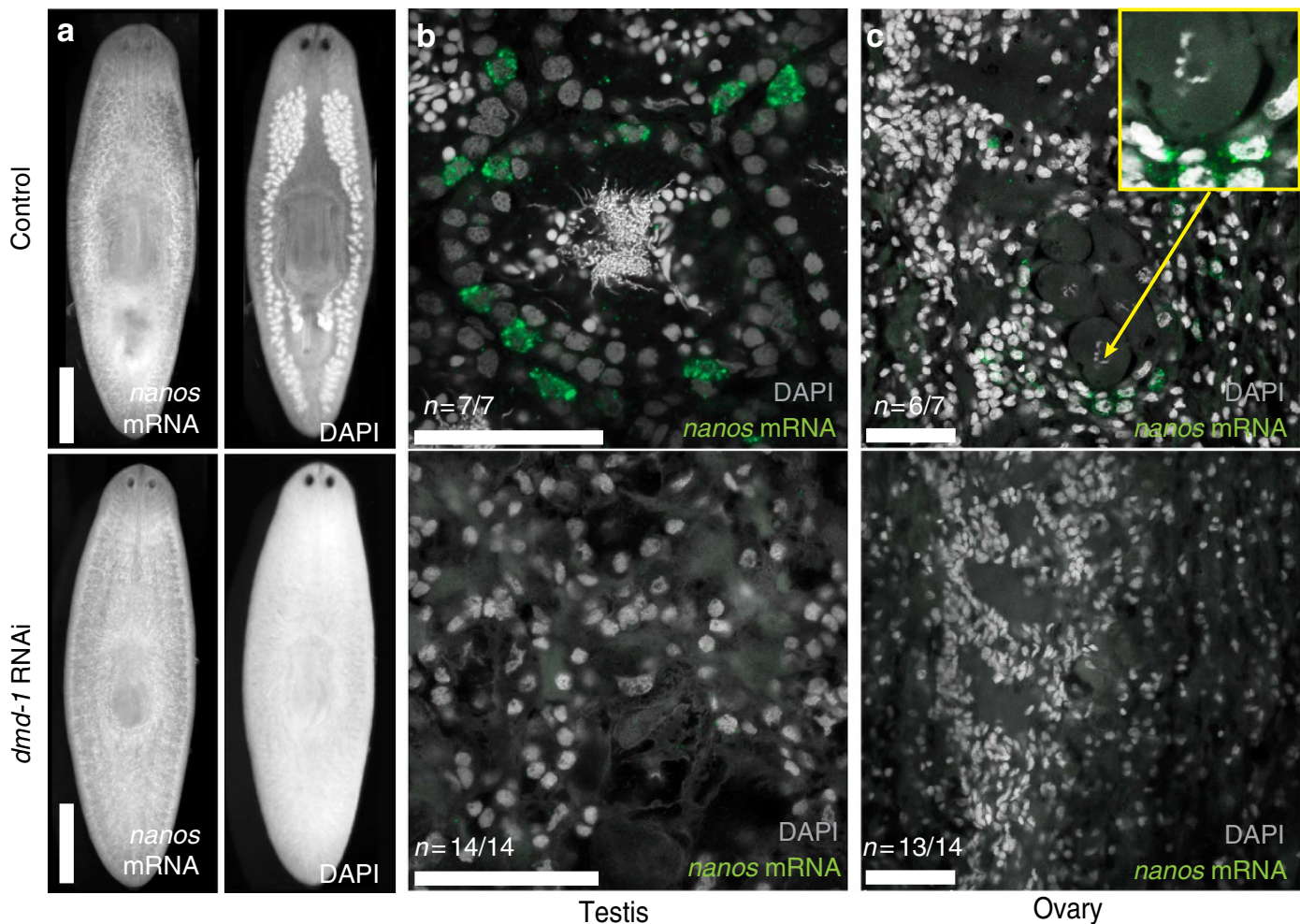

Figure 6 | dmd-1 is required for the initial development of the reproductive system. (a) Whole-mount images showing nanos transcripts (detected by FISH) present in control but not $d m d-1(R N A i)$ animals. The testes lobes are visible by 4',6-diamidino-2-phenylindole (DAPI) staining in the control but not $d m d-1$ (RNAi) animals. (b) The testes are absent and nanos-positive germline stem cells are not detected in dmd-1(RNAi) animals. (c) The ovaries are absent and nanos-positive germline stem cells are not detected in dmd-1(RNAi) animals. Inset, magnified view of oocyte. (b,c) Images shown are single confocal sections, nanos transcripts are detected by FISH. Scale bars: $\mathbf{a}, 1 \mathrm{~mm} ; \mathbf{b}, \mathbf{c}, 50 \mu \mathrm{m}$

the function of $d m d-1$ in animals that were regenerating their reproductive system (sexually immature regenerates, Supplementary Fig. S5). After 1 month of $d m d-1$ knockdown, most testes lobules in treated animals lacked spermatids and mature sperm. Animals treated for 3 months lost their testes entirely, including the nanos-positive germ cells. Ovaries, however, were normal in both control and $d m d-1$-knockdown animals, exhibiting nanos-positive germ cells and normal oocyte formation by $4^{\prime}, 6$-diamidino-2-phenylindole staining (Fig. 7b). These results suggest that $d m d-1$ is required for the differentiation of male germ cells during regeneration of the reproductive system.

We also examined the effect of $d m d-1$ knockdown on accessory organs associated with the male and female reproductive systems. Consistent with our observations on the male germline, knockdown of $d m d-1$ in sexually immature regenerates resulted in the absence of sperm ducts (Fig. 7c, black arrows) and seminal vesicles (Fig. 7c, asterisks), as visualized by ISH with eyes $a_{b s e n t}{ }^{36}$ (GenBank/EMBL/DDBJ accession number EG345430.1), a marker for oviducts, sperm ducts and seminal vesicles (Fig. 7c). Again, female structures were unaffected, as we found oviducts (white arrows) in both control and knockdown animals (Fig. 7c). Furthermore, dmd-1-knockdown animals still produced egg capsules (dmd-1 RNAi: 30 egg capsules, control: 26 egg capsules; 19 animals tracked from 6th to 9th feeding over 27 days), suggesting that not only oviducts, but all female organs responsible for egg production (for example, yolk glands and cement glands-Supplementary Fig. S6) are functional. These findings demonstrate that $d m d-1$ is a component of the pathway required for the differentiation of male accessory reproductive organs.
Sm_dmd-1 is expressed in male schistosomes. We have shown that regeneration and maintenance of male versus female reproductive organs in a simultaneous hermaphrodite are directed by distinct molecular pathways. The presence of sex-specific pathways involved in the regeneration and maintenance of reproductive organs provides a plausible mechanism for the evolution of distinct sexes from simultaneous hermaphrodites. Though organisms within the phylum Platyhelminthes are largely hermaphroditic ${ }^{37}$, members of the parasitic family Schistosomatidae exist as separate male and female sexes. The dioecy of schistosomes appears to be a derived feature of this clade $^{1}$ (Fig. 8a). Using qPCR, we found that in S. mansoni, the homologue of $d m d-1, S m \_d m d-1$ is dramatically upregulated in male schistosomes, relative to females (Fig. 8b); thus the sexspecific expression of $d m d-1$ is retained in a dioecious species of the flatworm phylum.

\section{Discussion}

The contrast between the male-specific role for $d m d-1$ in mature sexual worms, and its effect on both male and female systems in hatchlings is noteworthy. These different effects suggest a role for the male reproductive system in the subsequent development of the female system, consistent with the protandrous nature of sexual development in S. mediterranea. This idea is also supported by the male-specific expression of $d m d-1 \mathrm{mRNA}$, which is not detected in the ovaries of sexually mature animals, sexually immature regenerates or in hatchlings. Though we cannot exclude the possibilities that $d m d-1$ has a direct role in the initial differentiation of ovaries or that the male-specific phenotype in mature animals results from incomplete knockdown, the lack of $d m d-1$ expression 
a

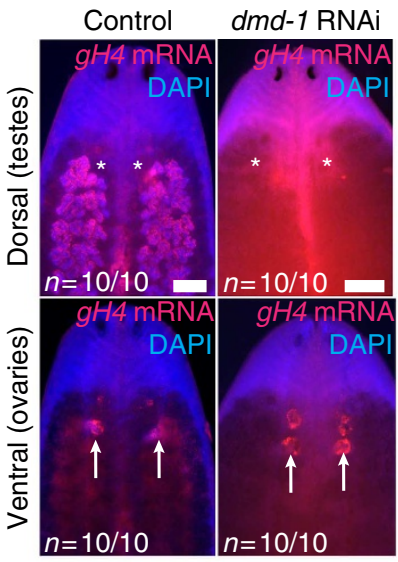

c

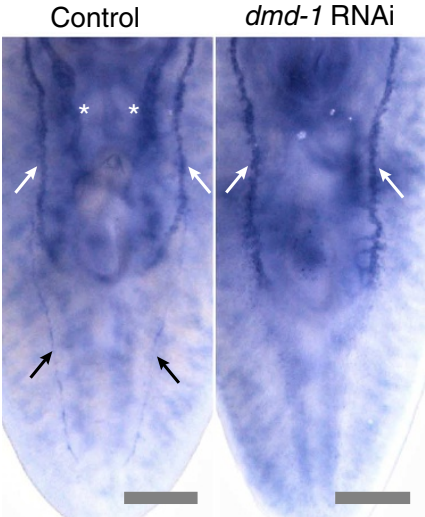

b

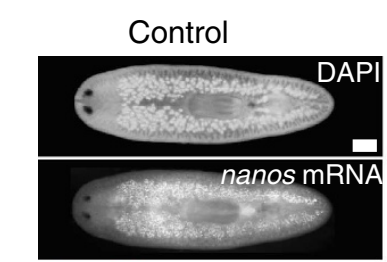

dmd-1 RNAi

(5 treatments)
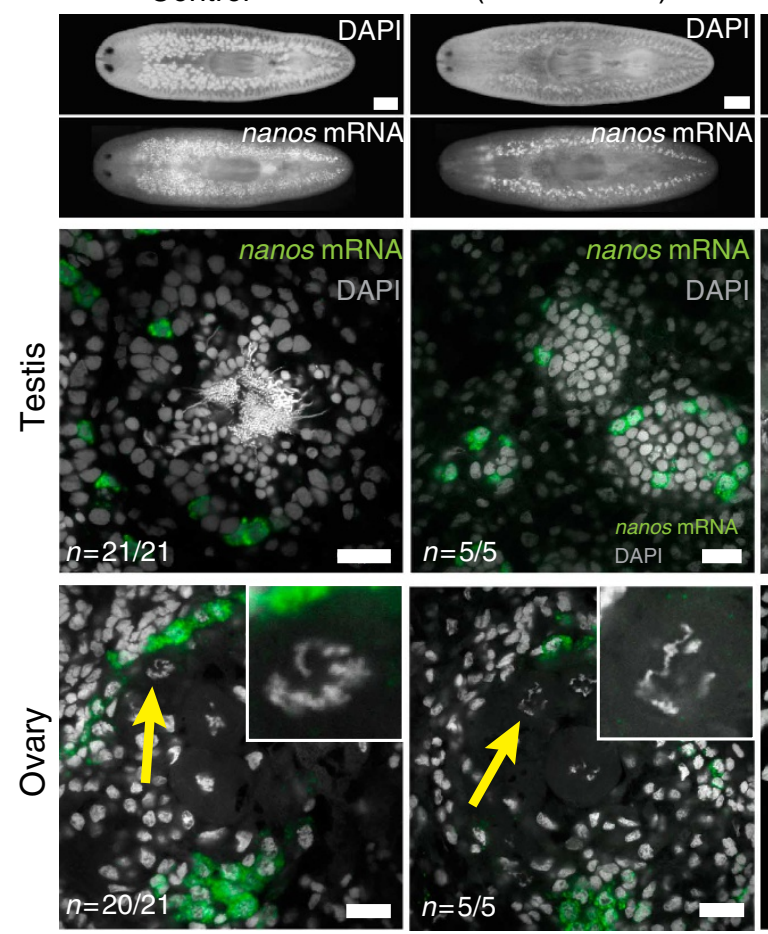

dmd-1 RNAi

(12-13 treatments)
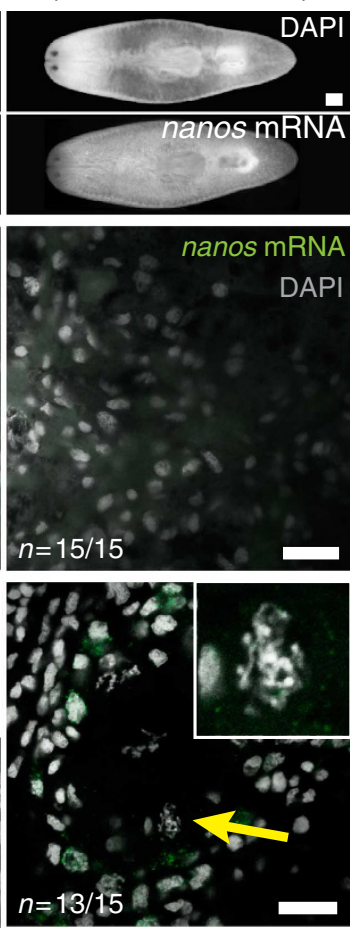

Figure 7 | dmd-1 is required for differentiation and maintenance of male germ cells. (a) FISH was performed to detect $g H 4$ transcripts in the testes and ovaries of control and dmd-7(RNAi) animals. Whole-mount images show the loss of testes in knockdown but not control animals; the ovaries are unaffected by the knockdown. (b) The testes and ovaries of control and dmd-1(RNAi) animals visualized by 4',6-diamidino-2-phenylindole (DAPI) and FISH to detect nanos transcripts. Top panels, whole-mount images showing the testes of control and knockdown animals after 5 or 12-13 RNAi treatments. Centre panels, single confocal sections showing dmd-1(RNAi) animals lacking differentiated germ cells in the testes (5 treatments, 1 month) or devoid of testes entirely (12-13 treatments, 3 months). Bottom panels, single confocal sections showing ovaries with normal oocyte formation (arrow, inset) in control and knockdown animals. (c) Sperm ducts (black arrows) and seminal vesicles (asterisks) are absent after dmd-1 RNAi, oviducts are unaffected ( $n=0 / 5$ had sperm ducts/seminal vesicles, compared with $5 / 5$ in controls; $n=4 / 5$ had oviducts, compared with $5 / 5$ in controls). These components of the male and female reproductive system were visualized by WISH to detect eyes absent transcripts. Scale bars $\mu \mathrm{m}: \mathbf{a}, \mathbf{b}$ (whole-mounts), c, $500 \mu \mathrm{m} ; \mathbf{b}, 20 \mu \mathrm{m}$.

in cells associated with female structures suggests that its effect on early ovarian development is an indirect consequence of impaired male development.

In other organisms, it has been shown that interaction between the nervous system and gonads is critical for sexual reproduction. In mammals, sexual maturation and maintenance of the gonads and reproductive structures are intimately tied to the neuroendocrine system ${ }^{38,39}$. Furthermore, sexually dimorphic neurons in Drosophila melanogaster and Caenorhabditis elegans regulate sexual behaviours ${ }^{40-44}$. In planarians, the relationship between the nervous system and reproductive system has been shown by experiments in which amputation of the brain leads to regression of the testes ${ }^{27,45}$. More recent work has demonstrated the role of neuropeptide signalling in regulating the planarian reproductive system, identifying a neuropeptide Y family member, NPY8, that is required for the development and maintenance of reproductive organs ${ }^{46}$. Interestingly, $d m d$-1-positive cells are detected in the planarian brain at all stages of development and regeneration, as well as in asexuals. These neurons may potentially regulate various aspects of male reproductive system development and/or sex-specific behaviours. Examining the role of the $d m d$-1-positive neurons will be an important direction for future research.

This work provides evidence for a conserved role of the DM domain gene family in sexual development in lophotrochozoans. To date, DM domain genes across the animal kingdom have been shown to function at different positions in the sexual development hierarchy. In the ecdysozoans C. elegans and D. melanogaster, DM domain proteins regulate the development of sexually dimorphic somatic features ${ }^{6,17}$. We have shown here that in planarians, a member of the lophotrochozoan clade, $d m d-1$ has a similar role-this transcription factor regulates the formation of male somatic structures like the penis papilla, sperm ducts and seminal vesicles. In addition, it is probable that $d m d-1$ in planarians acts cell non-autonomously to specify male germ cells and to regulate their differentiation and maintenance-roles more commonly found for DM domain proteins in vertebrates ${ }^{17,47}$. Elucidating the mechanisms by which $d m d-1$ functions in planarians will contribute to our understanding of how the DM domain gene family acts as a central factor in the evolution of sexual development across the metazoa. Furthermore, identifying the downstream targets of $d m d-1$ could help reveal the nature of the signal(s) that specify germ cells in planarians.

Previous studies in nematodes have shown that transitions between different mating systems can occur via mutations that affect the sex determination pathway and the regulation of gamete physiology with few pleiotropic effects on the organism $^{48,49}$. Phylogenetic analyses suggest that $d m d-1$ and $d m d-2$ in the schistosome, S. mansoni, are derived from an ancestral 

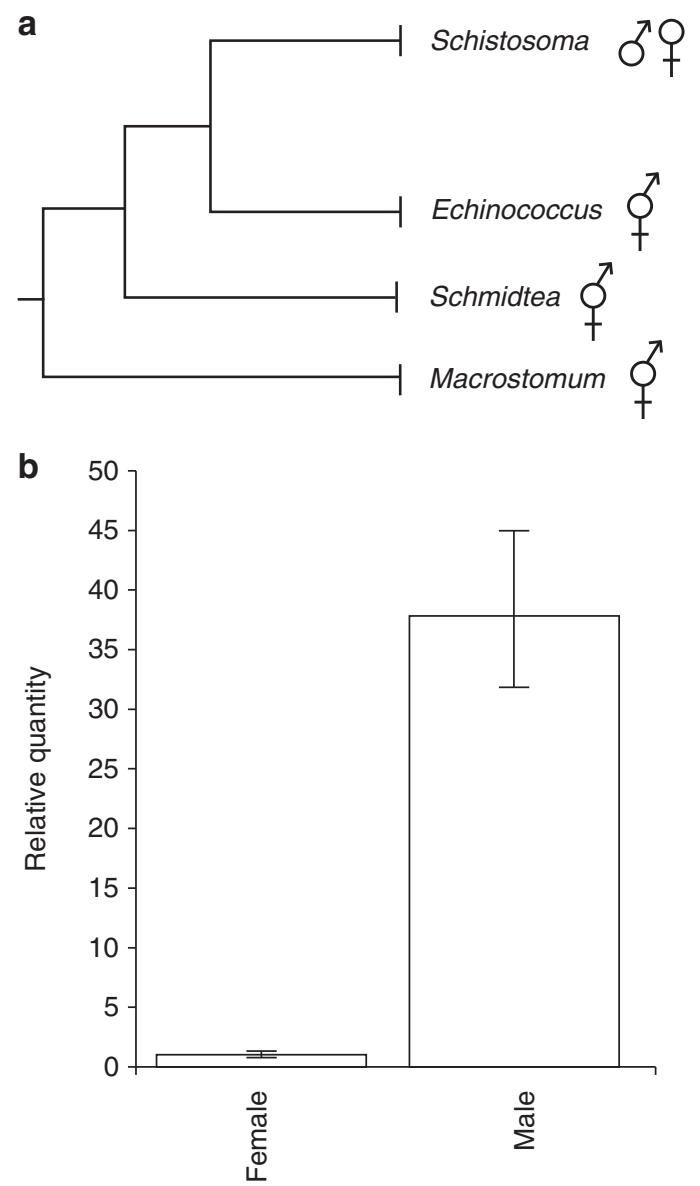

Figure 8 | A homologue of $d m d-1$ shows male-specific expression in the derived dioecious flatworm S. mansoni. (a) Simplified phylogenetic tree of the Platyhelminthes, adapted from Phylogenetic relationships of Platyhelminthes based on $18 \mathrm{~S}$ ribosomal gene sequences ${ }^{60}$. Members of the Platyhelminthes are largely hermaphroditic $(\xi)$; separate male $(\hbar)$ and female ( $q$ ) sexes in the schistosomes are a derived feature of this clade. (b) qPCR showing male-specific expression of a dmd-1 homologue in the male S. mansoni. Error bars indicate $95 \%$ confidence intervals calculated based on s.e.m., results are the mean from pools of male or female schistosomes harvested from three separate mice.

Platyhelminthes $d m d-1$ gene that duplicated in the trematode lineage after its divergence from the planarians (Supplementary Fig. S1). In the case of planarians and schistosomes, the malespecific expression of $d m d-1$ is conserved in a simultaneous hermaphrodite and a derived, dioecious flatworm. This conservation is consistent with the idea that independently regulated sex-specific developmental pathways could serve as plausible substrates for transitions between distinct mating systems. Further characterization of deeply conserved genes like $d m d-1$ that have sex-specific roles in simultaneous hermaphrodites and that retain sex-specific expression in dioecious species will provide a tractable system in which to investigate the transition from hermaphroditism to dioecy.

\section{Methods}

Planarian culture. Asexual planarians were maintained in $1 \times$ Montjuïc salts at $21^{\circ} \mathrm{C}$ (ref. 50) and sexual planarians in $0.75 \times$ Montjuic salts at $18^{\circ} \mathrm{C}$ (ref. 27). Animals were fed organic calf liver and starved at least 1 week before use.
Cloning of DM domain genes. mRNA sequences for $d m d-1,2$, 3 and 4 were determined using $5^{\prime}$ and/or $3^{\prime}$ RACE (RLM-Race kit, Ambion, Austin, TX) with total RNA extracted using Trizol Reagent (Invitrogen, Carlsbad, CA). PCR products were TA cloned (Rapid DNA Ligation Kit, Roche, Mannheim, Germany) into Eam11051-digested (Thermo Scientific, Logan, UT) pJC53.2 (Addgene ID: 26536) and transformed into DH5 $\alpha$ cells. Full-length $d m d-1$ complementary DNA was isolated by PCR amplification (Phusion High-Fidelity PCR Master Mix, Finnzymes, Vantaa, Finland), incubated with Taq polymerase and $10 \mathrm{mM}$ dATP, TA cloned into pJC53.2 and transformed into DH5 $\alpha$. Identity of clones was verified by sequencing. Primer sequences are listed in Supplementary Table S2.

Phylogenetic analyses. Eighty-four DM domain sequences from 74 proteins (ten had two DM domains) were obtained from the Pfam 26.0 database (http://pfam.sanger.ac.uk) and were aligned using CLUSTALW (ref. 51) (www.genome.jp/tools/clustalw/). Phylogenetic reconstruction was performed using MEGA 5.05 (ref. 52) to perform model testing and maximum likelihood testing. Model choice was performed using the Baysian information criterion to select the optimal model for aminoacid substitutions, which was the General Reverse Transcriptase model plus Gamma distributed rate variation ${ }^{53}$. Evolutionary history was inferred by maximum likelihood analysis. Nodal support was estimated using 500 bootstrap replicates. An initial tree for the heuristic search (using nearest neighbour interchange) was obtained automatically from a neighbour-joining tree. A discrete Gamma distribution was used to model evolutionary rate differences among sites (five categories; $+G$ parameter $=0.9267$ ). All ambiguous positions were removed for each sequence pair and there were a total of 55 positions in the final data set.

Irradiation. Asexual planarians were exposed to $100 \mathrm{~Gy}$ of gamma irradiation using a Gammacell 220 Excel with a cobalt-60 source (Nordion, Ottawa, ON, Canada) in $2 \mathrm{ml}$ of planarian salts and processed for RNA extraction or FISH at the specified time points.

RNAi analyses. Truncated $3^{\prime}$ RACE products cloned in pJC53.2 were used as templates to generate $d m d-1$ double-stranded RNA (dsRNA) (sequences in Supplementary Table S1). Animals were fed dsRNA-containing bacteria (hatchlings, sexually immature regenerates and mature adults) or dsRNA generated by in vitro transcription (IVT) (asexuals, mature adults and animals for de novo regeneration). Animals were fed sufficient dsRNA/liver to ensure excess after the animals had eaten.

To generate dsRNA by IVT, templates cloned into pJC53.2 were amplified with a modified T7 oligonucleotide (5'-GGATCCTAATACGACTCACTATAGGG- $3^{\prime}$ ) and cleaned up with the DNA Clean \& Concentrator kit (Zymo Research, Orange, CA, D4003 $)^{46}$. Each $20 \mu$ l IVT reaction $(2 \mu \mathrm{l} 10 \times$ high yield transcription buffer $\left(0.4 \mathrm{M}\right.$ Tris $\mathrm{pH} 8.0,0.1 \mathrm{M} \mathrm{MgCl}_{2}$, $20 \mathrm{mM}$ spermidine, $0.1 \mathrm{M}$ DTT), $5 \mu \mathrm{l} 25 \mathrm{mM}$ rNTP (Promega, Madison, WI), $1 \mu \mathrm{l}$ T7 polymerase, $1 \mu \mathrm{l}$ thermostable inorganic pyrophosphatase (TIPP, $2000 \mathrm{U} \mathrm{ml}^{-1}$ ) (New England Biolabs, Ipwich, MA), $0.5 \mu \mathrm{l}$ recombinant ribonuclease inhibitor (RNasin, $2500 \mathrm{U} \mathrm{ml}^{-1}$ ) (Promega) and $0.5-2.5 \mu \mathrm{g}$ of PCR product) was incubated at $37^{\circ} \mathrm{C}$ overnight, then treated with $1 \mu \mathrm{l}$ of $\mathrm{RQ} 1$ RNase-free DNase (Fisher Scientific, Pittsburgh, PA) for 20 min at room temperature ${ }^{54}$. Each reaction volume was brought up to $100 \mu$ l, followed by denaturating and annealing at the following temperatures: $95^{\circ} \mathrm{C}(3 \mathrm{~min}), 75^{\circ} \mathrm{C}(3 \mathrm{~min}), 50^{\circ} \mathrm{C}(3 \mathrm{~min})$ and room temperature $(5 \mathrm{~min})$. dsRNA was cleaned up by ammonium acetate precipitation $(2.5 \mathrm{M}$ final concentration of ammonium 
acetate, plus two volumes of $100 \%$ EtOH). $0.4-1 \mu \mathrm{g}$ dsRNA was mixed with $10 \mu \mathrm{l}$ of 3:1 liver:water mix. Control animals were fed dsRNA synthesized from the $c \mathrm{~dB}$ and camR-containing insert of pJC53.2.

To obtain dsRNA-containing bacteria, templates were shuttled to plasmid pPR244 using a Gateway reaction (Invitrogen) and transformed into E. coli strain HT115. dsRNA-containing bacteria was prepared by inoculating $30 \mathrm{ml}$ of $2 \mathrm{xYT}$ with kanamycin and tetracycline with $0.5 \mathrm{ml}$ of overnight culture. At $\mathrm{OD}_{0.3-0.4}$, cultures were induced with $0.4 \mathrm{M}$ isopropylthiogalactoside for $2 \mathrm{~h}$ (ref. 55). The bacterial pellet from $1.5 \mathrm{ml}$ of culture was mixed with $21 \mu \mathrm{l}$ of 3:1 liver:water mix. Control animals were fed bacteria-containing empty pPR242 vector.

Feeding schedules are provided in Supplementary Table S3.

Quantitative real-time PCR. To measure relative mRNA levels, total RNA was extracted from animals 7-9 days after the final dsRNA feed and reverse transcribed. qPCR was performed on an Applied Biosystems StepOne Plus Real-Time PCR system using GoTaq qPCR Master Mix with SYBR green (Promega). Triplicates were done for all samples to account for errors in pipetting. Transcript levels were normalized to $\beta$-tubulin [GB:DN305397] (planarians) and Sm_cytochrome $c$ oxidase I [Smp_900000, GB:AF216698.1] (schistosomes). Relative quantities were calculated using the $\Delta \Delta \mathrm{Ct}$ calculation in the StepOne Plus Software. Oligonucleotide primer sequences are listed in Supplementary Table S2.

Riboprobe synthesis and in situ hybridization. Full-length $d m d-1$ in pJC53.2 was used as template to generate riboprobes for in situ hybridization (ISH). IVT reactions with T3 RNA polymerase were performed using standard approaches with either digoxigenin-12-UTP (Roche), fluorescein-12-UTP (Roche) or dinitrophenol-11-UTP (PerkinElmer, Waltham, MA). Riboprobes were synthesized for $4-5 \mathrm{~h}$ at $37^{\circ} \mathrm{C}$, treated with RNase-free DNase (Fisher Scientific, Pittsburgh, PA), and precipitated with ammonium acetate and ethanol.

For whole-mount ISH, animals were killed with 5-10\% $\mathrm{N}$-acetyl-cysteine (Sigma-Aldrich, St. Louis, MO) for 8-11 min, then fixed in $4 \%$ formaldehyde in PBTx $(1 \times$ PBS $+0.3 \%$ Triton $\mathrm{X}-100)$ for $20-30 \mathrm{~min}$ at room temperature ${ }^{56}$. The strength and times of treatment/fixation was dependent on size and condition (regenerating versus intact) of the animals. Animals were bleached in $6 \% \mathrm{H}_{2} \mathrm{O}_{2}$ in $\mathrm{MeOH}$ overnight ${ }^{56}$ or in formamide/ $\mathrm{H}_{2} \mathrm{O}_{2}$ for 2-3 h (ref. 57). Before bleaching in $\mathrm{H}_{2} \mathrm{O}_{2}$ in $\mathrm{MeOH}$, animals were permeabilized and reduced ${ }^{56}$. Following bleaching, animals were treated with Proteinase $\mathrm{K}\left(5-10 \mu \mathrm{g} \mathrm{ml}^{-1}, 20 \mathrm{~min}-\right.$ $1 \mathrm{~h}$, depending on size and condition) followed by post-fixation ${ }^{56}$. Riboprobe concentration for hybridization ranged from $0.1-0.3 \mathrm{ng}^{-1}$. Following post-hybridization washes and blocking, animals were incubated in either anti-digoxigenin alkaline phosphatase (1:2,000 (Roche)), anti-digoxigenin peroxidase (1:1,000 (Roche)), anti-fluorescein peroxidase $(1: 1,000$ (Roche) $)$ or anti-dinitrophenol peroxidase $(1: 100$ (PerkinElmer)) overnight at $4{ }^{\circ} \mathrm{C}$. Samples were washed and developed with Fluorescein-, Cy3- or TAMRA-Tyramide using the manufacturer's protocol (PerkinElmer) ${ }^{29}$ or in TSA buffer $(2 \mathrm{M} \mathrm{NaCl}, 0.1 \mathrm{M} \text { Boric acid, } \mathrm{pH} 8.5)^{57}$. For two-colour ISH, the peroxidase after the first tyramide development was quenched with either $2 \% \mathrm{H}_{2} \mathrm{O}_{2}$ in PBTX, $1 \mathrm{~h}$ or $0.1 \%$ sodium azide in $1 \times$ PBS, $30 \mathrm{~min}$, followed by several washes before subsequent antibody incubation.

Imaging. WISH images were captured on a Leica DFC420 camera mounted on a Leica M205A stereomicroscope (Leica,
Wetzlar, Germany). Samples were mounted in $80 \%$ glycerol/ PBTx.

Whole-mount FISH images were imaged on a Zeiss Stereo Lumar V12 (Carl Zeiss, Germany). Samples were mounted in Vectashield (Vector Laboratories, Burlingame, CA).

Confocal FISH images were obtained on a Zeiss LSM 710 confocal microscope (Carl Zeiss), (Plan-Apochromat $10 \times / 0.45$, Plan-Apochromat $20 \times / 0.8$, C-Apochromat $40 \times / 1.2 \mathrm{~W}$ korr UV-vis-IR or Plan-Apochromat $63 \times / 1.4$ Oil DIC objectives). Samples were mounted in Vectashield. Fluorescein, Cy3/5TAMRA and Cy5 were excited with 488, 561 and $633 \mathrm{~nm}$ lasers, respectively.

Images were processed (cropping and annotation; brightness and contrast adjustments to entire image) using Adobe Photoshop CS4/CS5 and/or Zen 2008/9/11.

Electron microscopy. Asexual worms were fixed in cold 2\% formaldehyde, $2.5 \%$ glutaraldehyde in EMBuffer $(70 \mathrm{mM}$ sodium cacodylate, $1 \mathrm{mM} \mathrm{CaCl}_{2}$, $\mathrm{pH} 7.4$ ), excised, fixed for four additional hours, washed twice in EMBuffer and post-fixed $\left(1 \% \mathrm{OsO}_{4}\right.$, $90 \mathrm{~min}, 4^{\circ} \mathrm{C}$ in dark). Animals were dehydrated $(20+2 \%$ uranyl acetate, $40,60,80,100 \%$ ethanol), placed in acetone, and infiltrated with epoxy-embedding resin ${ }^{58}$. Thin $(60-90 \mathrm{~nm})$ sections were collected on Formvar-coated copper slot grids (Electron Microscopy Sciences, Hatfield, PA) and stained ${ }^{58}$. Images were acquired with a Hitachi H-7000 STEM electron microscope in transmission mode, at an accelerating voltage of $75 \mathrm{kV}$. All chemicals were obtained from Polysciences (Warrington, PA) unless otherwise noted.

Parasite acquisition and culture. Adult S. mansoni (7 weeks post infection) were obtained from infected mice by hepatic portal vein perfusion ${ }^{59}$ with $37^{\circ} \mathrm{C}$ DMEM (Mediatech, Manassas, VA) plus $5 \%$ fetal calf serum (FBS, Hyclone/Thermo Scientific). Parasites were rinsed several times in DMEM $+5 \%$ FBS, male and female parasites were separated by incubation (2-3 min) in a $0.25 \%$ solution of the anaesthetic ethyl 3-aminobenzoate methanesulfonate (Sigma-Aldrich) in DMEM + 5\% FBS.

Vertebrate animal care. In adherence to the Animal Welfare Act and the Public Health Service Policy on Humane Care and Use of Laboratory Animals, all experiments with and care of vertebrate animals were performed in accordance with protocols approved by the Institutional Animal Care and Use Committee (IACUC) of the University of Illinois at Urbana-Champaign (protocol approval number 10035).

\section{References}

1. Basch, P. F. Why do schistosomes have separate sexes? Parasitol. Today 6, 160-163 (1990).

2. Kiontke, K. et al. Caenorhabditis phylogeny predicts convergence of hermaphroditism and extensive intron loss. Proc. Natl Acad. Sci. USA 101, 9003-9008 (2004).

3. Eppley, S. M. \& Jesson, L. K. Moving to mate: the evolution of separate and combined sexes in multicellular organisms. J. Evol. Biol. 21, 727-736 (2008).

4. Bull, J. J. Sex determination in reptiles. Q. Rev. Biol. 55, 3-21 (1980).

5. Koopman, P., Munsterberg, A., Capel, B., Vivian, N. \& Lovell-Badge, R. Expression of a candidate sex-determining gene during mouse testis differentiation. Nature 348, 450-452 (1990).

6. Williams, T. M. \& Carroll, S. B. Genetic and molecular insights into the development and evolution of sexual dimorphism. Nat. Rev. Genet. 10, 797-804 (2009).

7. Kimble, J. \& Crittenden, S. L. Controls of germline stem cells, entry into meiosis, and the sperm/oocyte decision in Caenorhabditis elegans. Annu. Rev. Cell. Dev. Biol. 23, 405-433 (2007).

8. Kimble, J. \& Page, D. C. The mysteries of sexual identity. The germ cell's perspective. Science 316, 400-401 (2007). 
9. Blackler, A. W. Germ-cell transfer and sex ratio in Xenopus Laevis. J. Embryol. Exp. Morphol. 13, 51-61 (1965).

10. Hilfiker-Kleiner, D., Dubendorfer, A., Hilfiker, A. \& Nothiger, R. Genetic control of sex determination in the germ line and soma of the housefly, Musca domestica. Development 120, 2531-2538 (1994).

11. Casper, A. L. \& Van Doren, M. The establishment of sexual identity in the Drosophila germline. Development 136, 3821-3830 (2009).

12. Durcova-Hills, G. \& Capel, B. Development of germ cells in the mouse. Curr. Top. Dev. Biol. 83, 185-212 (2008).

13. Steinmann-Zwicky, M., Schmid, H. \& Nothiger, R. Cell-autonomous and inductive signals can determine the sex of the germ line of Drosophila by regulating the gene Sxl. Cell 57, 157-166 (1989).

14. Kato, Y., Kobayashi, K., Watanabe, H. \& Iguchi, T. Environmental sex determination in the branchiopod crustacean Daphnia magna: deep conservation of a Doublesex gene in the sex-determining pathway. PLoS Genet. 7, e1001345 (2011).

15. Matson, C. K. et al. The mammalian doublesex homolog DMRT1 is a transcriptional gatekeeper that controls the mitosis versus meiosis decision in male germ cells. Dev. Cell 19, 612-624 (2010).

16. Matson, C. K. et al. DMRT1 prevents female reprogramming in the postnatal mammalian testis. Nature 476, 101-104 (2011).

17. Matson, C. K. \& Zarkower, D. Sex and the singular DM domain: insights into sexual regulation, evolution and plasticity. Nat. Rev. Genet. 13, 163-174 (2012).

18. Matsuda, M. et al. DMY is a Y-specific DM-domain gene required for male development in the medaka fish. Nature 417, 559-563 (2002).

19. Miller, S. W. et al. A DM domain protein from a coral, Acropora millepora, homologous to proteins important for sex determination. Evol. Dev. 5, 251-258 (2003).

20. Raymond, C. S. et al. Evidence for evolutionary conservation of sexdetermining genes. Nature 391, 691-695 (1998).

21. Smith, C. A. et al. The avian Z-linked gene DMRT1 is required for male sex determination in the chicken. Nature 461, 267-271 (2009).

22. Altschul, S. F., Gish, W., Miller, W., Myers, E. W. \& Lipman, D. J. Basic local alignment search tool. J. Mol. Biol. 215, 403-410 (1990).

23. Volff, J. N., Zarkower, D., Bardwell, V. J. \& Schartl, M. Evolutionary dynamics of the DM domain gene family in metazoans. J. Mol. Evol. 57(Suppl 1): S241-S249 (2003).

24. Newmark, P. A., Wang, Y. \& Chong, T. Germ cell specification and regeneration in planarians. Cold Spring Harb. Symp. Quant. Biol. 73, 573-581 (2008).

25. Handberg-Thorsager, M. \& Salo, E. The planarian nanos-like gene Smednos is expressed in germline and eye precursor cells during development and regeneration. Dev. Genes Evol. 217, 403-411 (2007).

26. Sato, K. et al. Identification and origin of the germline stem cells as revealed by the expression of nanos-related gene in planarians. Dev. Growth Differ. 48, 615-628 (2006)

27. Wang, Y., Zayas, R. M., Guo, T. \& Newmark, P. A. nanos function is essential for development and regeneration of planarian germ cells. Proc. Natl Acad. Sci. USA 104, 5901-5906 (2007).

28. Chong, T., Stary, J. M., Wang, Y. \& Newmark, P. A. Molecular markers to characterize the hermaphroditic reproductive system of the planarian Schmidtea mediterranea. BMC Dev. Biol. 11, 69 (2011).

29. Wang, Y., Stary, J. M., Wilhelm, J. E. \& Newmark, P. A. A functional genomic screen in planarians identifies novel regulators of germ cell development. Genes Dev. 24, 2081-2092 (2010).

30. Roberts-Galbraith, R. H. \& Newmark, P. A. Follistatin antagonizes Activin signaling and acts with Notum to direct planarian head regeneration. Proc. Natl Acad. Sci. USA 110, 1363-1368 (2013).

31. Wenemoser, D. \& Reddien, P. W. Planarian regeneration involves distinct stem cell responses to wounds and tissue absence. Dev. Biol. 344, 979-991 (2010).

32. Wagner, D. E., Wang, I. E. \& Reddien, P. W. Clonogenic neoblasts are pluripotent adult stem cells that underlie planarian regeneration. Science 332, 811-816 (2011)

33. Eisenhoffer, G. T., Kang, H. \& Sanchez Alvarado, A. Molecular analysis of stem cells and their descendants during cell turnover and regeneration in the planarian. Schmidtea mediterranea. Cell Stem Cell 3, 327-339 (2008).

34. Reddien, P. W., Oviedo, N. J., Jennings, J. R., Jenkin, J. C. \& Sanchez Alvarado, A. SMEDWI-2 is a PIWI-like protein that regulates planarian stem cells. Science 310, 1327-1330 (2005).

35. Guo, T., Peters, A. H. F. M. \& Newmark, P. A. A Bruno-like gene is required for stem cell maintenance in planarians. Dev. Cell 11, 159-169 (2006).

36. Scimone, M. L., Srivastava, M., Bell, G. W. \& Reddien, P. W. A regulatory program for excretory system regeneration in planarians. Development 138, 4387-4398 (2011).

37. Hyman, L. The Invertebrates, Vol II: Platyhelminthes and Rhynchocoela (McGraw-Hill Book Company, Inc., New York, 1951).

38. Schwartz, N. B. \& McCormack, C. E. Reproduction: gonadal function and its regulation. Annu. Rev. Physiol. 34, 425-472 (1972).
39. Steinberger, E. Hormonal control of mammalian spermatogenesis. Physiol. Rev. 51, 1-22 (1971).

40. Kimura, K., Hachiya, T., Koganezawa, M., Tazawa, T. \& Yamamoto, D. Fruitless and doublesex coordinate to generate male-specific neurons that can initiate courtship. Neuron 59, 759-769 (2008).

41. Rezaval, C. et al. Neural circuitry underlying Drosophila female postmating behavioral responses. Curr. Biol. 22, 1155-1165 (2012).

42. Barrios, A., Nurrish, S. \& Emmons, S. W. Sensory regulation of C. elegans male mate-searching behavior. Curr. Biol. 18, 1865-1871 (2008).

43. Portman, D. S. Genetic control of sex differences in C. elegans neurobiology and behavior. Adv. Genet. 59, 1-37 (2007).

44. White, J. Q. \& Jorgensen, E. M. Sensation in a single neuron pair represses male behavior in hermaphrodites. Neuron 75, 593-600 (2012).

45. Ghirardelli, E. Regeneration in Animals and Related Problems 177-184 (NorthHolland Publishing Co., Amsterdam, 1965).

46. Collins, III J. J. et al. Genome-wide analyses reveal a role for peptide hormones in planarian germline development. PLoS Biol. 8, e1000509 (2010).

47. Zarkower, D. DMRT genes in vertebrate gametogenesis. Curr. Top. Dev. Biol. 102, 327-356 (2013).

48. Braendle, C. \& Felix, M. A. Sex determination: ways to evolve a hermaphrodite. Curr. Biol. 16, R468-R471 (2006).

49. Baldi, C., Cho, S. \& Ellis, R. E. Mutations in two independent pathways are sufficient to create hermaphroditic nematodes. Science 326, 1002-1005 (2009).

50. Cebrià, F. \& Newmark, P. A. Planarian homologs of netrin and netrin receptor are required for proper regeneration of the central nervous system and the maintenance of nervous system architecture. Development 132, 3691-3703 (2005).

51. Larkin, M. A. et al. Clustal W and Clustal X version 2.0. Bioinformatics 23, 2947-2948 (2007).

52. Tamura, K. et al. MEGA5: molecular evolutionary genetics analysis using maximum likelihood, evolutionary distance, and maximum parsimony methods. Mol. Biol. Evol. 28, 2731-2739 (2011).

53. Dimmic, M. W., Rest, J. S., Mindell, D. P. \& Goldstein, R. A. rtREV: an amino acid substitution matrix for inference of retrovirus and reverse transcriptase phylogeny. J. Mol. Evol. 55, 65-73 (2002).

54. Rouhana, L. et al. RNA interference by feeding in vitro synthesized doublestranded RNA to planarians: Methodology and dynamics. Dev. Dyn. (e-pub ahead of print 26 February 2013; doi:10.1002/dvdy.23950).

55. Reddien, P. W., Bermange, A. L., Murfitt, K. J., Jennings, J. R. \& Sanchez Alvarado, A. Identification of genes needed for regeneration, stem cell function, and tissue homeostasis by systematic gene perturbation in planaria. Dev. Cell 8 , 635-649 (2005)

56. Pearson, B. J. et al. Formaldehyde-based whole-mount in situ hybridization method for planarians. Dev. Dyn. 238, 443-450 (2009).

57. King, R. S. \& Newmark, P. A. An in situ hybridization protocol for enhanced detection of gene expression in the planarian Schmidtea mediterranea. BMC Dev. Biol. 13, 8 (2013).

58. Rouhana, L., Vieira, A. P., Roberts-Galbraith, R. H. \& Newmark, P. A. PRMT5 and the role of symmetrical dimethylarginine in chromatoid bodies of planarian stem cells. Development 139, 1083-1094 (2012).

59. Lewis, F. Schistosomiasis. Curr. Protoc. Immunol Chapter 19, Unit 191 (2001).

60. Campos, A., Cummings, M. P., Reyes, J. L. \& Laclette, J. P. Phylogenetic relationships of platyhelminthes based on $18 \mathrm{~S}$ ribosomal gene sequences. Mol. Phylogenet. Evol. 10, 1-10 (1998).

\section{Acknowledgements}

We thank James Sikes and Labib Rouhana for discussion and comments on the project and manuscript, Ryan King for ideas on in situ optimization, Jason Wever for providing the eyes absent construct, Rachel Roberts-Galbraith and Nayab Abidi for clones and assistance with neuronal markers, Melanie Issigonis for assistance with qPCR analyses, and members of the Newmark Lab for discussion and support; Peter Reddien, Whitehead Institute/Massachusetts Institute of Technology, for the pPR242 RNAi feeding vector; Tony Gamble, University of Minnesota, for advice and assistance with phylogenetic analysis of DM domains. This work was supported by NIH (R01 HD043403 and R21 AI099642), NSF (IOS-0744689), and a Richard and Margaret Romano Professorial Scholar Award to P.A.N. and NIH (R01 GM059152) to D.Z. P.A.N is an investigator of the Howard Hughes Medical Institute.

\section{Author contributions}

T.C. carried out all the experiments on S. mediterranea and drafted the manuscript. J.J.C performed all experiments associated with S. mansoni. J.L.B. performed TEM studies on asexual planarians. D.Z. performed phylogenetic analysis on DM domains and wrote the corresponding section. T.C., J.J.C. and P.A.N. designed the study and prepared the manuscript. All authors read and approved the manuscript. 


\section{Additional information}

Accession Codes: Sequence data have been deposited in GenBank/EMBL/DDBJ under accession numbers KC736555 ( $d m d-1$ splice form 1), KC736556 (dmd-1 splice form 2), KC736557 (dmd-1 splice form 3), KC736558 (dmd-1 splice form 4), KC736559 (dmd-2 splice form 1), KC736560 (dmd-2 splice form 2), KC736561 (dmd-3) and KC736562 $(d m d-4)$.

Supplementary Information accompanies this paper at http://www.nature.com/ naturecommunications

Competing financial interests: The authors declare no competing financial interests.
Reprints and permission information is available online at http://npg.nature.com/ reprintsandpermissions/

How to cite this article: Chong, T. et al. A sex-specific transcription factor controls male identity in a simultaneous hermaphrodite. Nat. Commun. 4:1814 doi: 10.1038/ ncomms2811 (2013).

(c) (1) () $\Theta$ This work is licensed under a Creative Commons Attributioncc) No No No Nommercial-NoDerivs 3.0 Unported License. To view a copy of this license, visit http://creativecommons.org/licenses/by-nc-nd/3.0/ 